\title{
The relationship between maternal plasma homocysteine in early pregnancy and birth weight
}

\author{
Shona Cawley \\ Technological University Dublin, shona.cawley@tudublin.ie \\ Eimer O'Malley \\ University College Dublin, Ireland \\ Rachel Kennedy \\ Technological University Dublin
}

See next page for additional authors

Follow this and additional works at: https://arrow.tudublin.ie/scschbioart

Part of the Biology Commons, Maternal and Child Health Commons, and the Women's Health

Commons

\section{Recommended Citation}

Shona Cawley, Eimer G. O'Malley, Rachel A. K. Kennedy, Ciara M. E. Reynolds, Anne M. Molloy \& Michael J. Turner (2020) The relationship between maternal plasma homocysteine in early pregnancy and birth weight, The Journal of Maternal-Fetal \& Neonatal Medicine, 33:18, 3045-3049, DOI: 10.1080/

14767058.2019.1567705

This Article is brought to you for free and open access by the School of Biological Sciences at ARROW@TU Dublin. It has been accepted for inclusion in Articles by an authorized administrator of ARROW@TU Dublin. For more information, please contact arrow.admin@tudublin.ie, aisling.coyne@tudublin.ie,gerard.connolly@tudublin.ie. Funder: Safefood

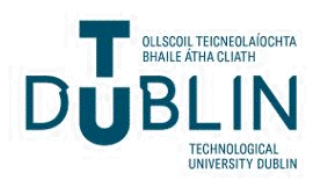




\section{Authors}

Shona Cawley, Eimer O'Malley, Rachel Kennedy, Ciara Reynolds, Anne Molloy, and Michael Turner

This article is available at ARROW@TU Dublin: https://arrow.tudublin.ie/scschbioart/288 


\section{The relationship between maternal plasma homocysteine in early pregnancy and birth weight}

Shona Cawley, Eimer G. O’Malley, Rachel A. K. Kennedy, Ciara M. E. Reynolds, Anne M. Molloy \& Michael J. Turner

To cite this article: Shona Cawley, Eimer G. O'Malley, Rachel A. K. Kennedy, Ciara M. E. Reynolds, Anne M. Molloy \& Michael J. Turner (2020) The relationship between maternal plasma homocysteine in early pregnancy and birth weight, The Journal of Maternal-Fetal \& Neonatal Medicine, 33:18, 3045-3049, DOI: 10.1080/14767058.2019.1567705

To link to this article: https://doi.org/10.1080/14767058.2019.1567705

View supplementary material $[7$

Published online: 29 Jan 2019.

Submit your article to this journal

Џ Article views: 212

Q View related articles

View Crossmark data $\nearrow$

Citing articles: 2 View citing articles 지 


\title{
The relationship between maternal plasma homocysteine in early pregnancy and birth weight
}

\author{
Shona Cawley ${ }^{a, b}$, Eimer G. O'Malley ${ }^{a}$ (D), Rachel A. K. Kennedy ${ }^{a, b}$, Ciara M. E. Reynolds ${ }^{a}$, Anne M. Molloy \\ and Michael J. Turner ${ }^{\mathrm{a}}$ \\ a UCD Centre for Human Reproduction, Coombe Women and Infants, University Hospital, Dublin, Ireland; 'b School of Biological \\ Sciences, Dublin Institute of Technology, Dublin, Ireland; 'School of Medicine, Trinity College Dublin, Dublin, Ireland
}

\begin{abstract}
Background: There is limited evidence that plasma homocysteine (Hcy) is increased in women with adverse pregnancy outcomes, such as low birth weight (LBW).

Objective: We examined the relationship between maternal Hcy at the first prenatal visit and birth weight.

Study design: In a prospective observational study, women were recruited during their first prenatal visit after sonographic confirmation of gestational age. Along with the standard tests, blood was also taken for the measurement of maternal serum and red blood cell (RBC) folate, vitamin B12, and Hcy. In addition to collecting standard clinical and sociodemographic details, a detailed questionnaire on vitamin supplementation was completed under supervision. Birth outcomes were collected immediately after delivery.

Results: Of 498 women recruited, 213 (42.8\%) were nulliparous, 97 (19.4\%) were obese, 64 (12.9\%) selfreported as current smokers, and 489 (98.2\%) were taking folic acid (FA) supplements at presentation. The mean (SD) birth weight was $3426.3 \mathrm{~g}(600.7), 14.0 \%$ of infants were small for gestational age, and $7.4 \%$ were large for gestational age. Mean (SD) plasma Hcy was 7.1 (2.1) $\mu \mathrm{mol} / \mathrm{l}$. On multiple linear regression, higher plasma Hcy was associated with selfreported smoking $(p=.009)$, relative income poverty $(p=.037)$ and Irish nativity $(p=.009)$. There was no relationship between maternal plasma Hcy and birth weight centile, either overall or when analyzed separately for either smokers $(r=0.0001, p=.98)$ and nonsmokers $(r=-0.007, p=.097)$. Plasma Hcy was correlated negatively with serum folate, RBC folate, and serum vitamin B12. There was no association between maternal Hcy and the duration of FA supplementation in weeks $(r=-0.08, p=.083)$ or between maternal Hcy and gestational age at phlebotomy $(r=-0.54, p=.35)$.

Conclusions: In this well-characterized cohort of women in early pregnancy, there was no correlation between maternal plasma Hcy and birth weight. However, higher Hcy was associated with maternal smoking and social deprivation which may explain the association reported previously between an increased Hcy and LBW.

Rationale

This study was conducted to investigate the relationship between maternal homocysteine in early pregnancy and infant birth weight. Increased plasma homocysteine in early pregnancy was not associated with a lower birth weight. However, there was a positive correlation between increasing plasma homocysteine and maternal smoking and social disadvantage which are risk factors for lower birth weight. This study highlights the importance of correcting for confounding variables, such as smoking and social disadvantage, when evaluating the relationship maternal nutritional biomarkers and intrauterine fetal development.
\end{abstract}

\section{RATIONALE}

This study was conducted to investigate the relationship between maternal homocysteine in early pregnancy and infant birth weight. Increased plasma homocysteine in early pregnancy was not associated with a lower birth weight. However, there was a positive correlation between increasing plasma homocysteine and maternal smoking and social disadvantage which are risk factors for lower birth weight. This study highlights the importance of correcting for confounding variables, such as smoking and social disadvantage, when evaluating the relationship maternal nutritional biomarkers and intrauterine fetal development.
ARTICLE HISTORY

Received 8 February 2018 Revised 12 December 2018 Accepted 7 January 2019

\section{KEYWORDS}

Birth weight; early pregnancy; maternal folate; maternal homocysteine; maternal vitamin B12

CONTACT Eimer O'Malley Research eimer.om@gmail.com $=$ UCD Centre for Human Reproduction, Coombe Women and Infants University Hospital, Dublin 8, Ireland

(4) Supplemental data for this article is available online at here. 


\section{Introduction}

Homocysteine (Hcy) is a sulfur-containing amino acid that is a demethylated derivative of methionine and which is not used in protein synthesis [1]. It is metabolized by two main pathways: remethylation to methionine or, transsulphuration to cystathionine and then to cysteine [2]. The conversion of Hcy to methionine is the only human reaction that requires both folate and vitamin B12 as cofactors. A defect in either of the main pathways leads to an accumulation of Hcy. The defect may be congenital or due to deficiencies in micronutrients. Deficiencies in folate or vitamin B12 compromise the remethylation pathway. Deficiencies in vitamin B6 compromise the transsulphuration pathway [3].

Plasma Hcy is $30-60 \%$ lower in pregnancy $[1,4,5]$. This may be explained by the many physiological changes in pregnancy including the haemodilutional changes in albumin levels as $70-80 \%$ of Hcy is bound to albumin. Several longitudinal studies found that total Hcy levels were lower in the second trimester but increased in the third trimester [4,5]. Interpretation of maternal plasma Hcy levels, therefore, depend on the timing of sampling in relationship to gestational age.

Plasma Hcy levels are correlated negatively with plasma vitamin B12, plasma folate, and folate during pregnancy [4]. Hcy levels are decreased in women taking Folic acid (FA) supplementation and are increased in women with pregnancies complicated by neural tube defects (NTDs) compared with controls $[6,7]$. In a meta-analysis involving mothers of 1304 NTD cases in 17 studies between 1966 and 2015, the increase in Hcy was associated with an increased risk of NTDs; however, this was not significant in the four countries where folate fortification was mandatory [7]. It should be noted that 11 of the 17 studies in the meta-analysis measured Hcy after delivery. None of the studies reported on measurements from pregnancies in the first trimester [7]. An increased Hcy level has also been associated with intrauterine fetal growth restriction [5].

Previous studies have demonstrated an association between increasing $\mathrm{Hcy}$ and low birth weight. A study of 100 women measured serum Hcy at 8-12-week gestation and reported an association between higher Hcy in the first trimester and delivery of a low birth weight baby (birth weight $\geq 2500 \mathrm{~g}$; mean Hcy $12.35 \pm 5.64 \mu \mathrm{mol} / \mathrm{L}$ and birth weight $<2500 \mathrm{~g}$; mean Hcy $23.22 \pm 12.32 \mu \mathrm{mol} / \mathrm{L}, p=.0224$ ) [8]. There was no correction for any potential confounding factors reported.

A study of 700 women in India measured vitamin B12, Hcy, and folate at 18 and 28 weeks gestation [9].
Almost one-third (28\%) of the study population had a Hcy level $>10 \mu \mathrm{mol} / \mathrm{L}$ at 18 weeks while $60 \%$ were deficient in vitamin $\mathrm{B} 12$ and just one had a red blood cell (RBC) folate level considered deficient. They found an association between increased Hcy at 18-week gestation and a smaller newborn size based on the measurement of anthropometric measurements of midupper arm circumference $(p=.02)$, abdominal circumference $(p=.02)$, and subscapular and triceps skinfold thickness ( $p=.001$ and $p=.007$ respectively). This study does not report the association with the fetal weight or comment on the incidence of smoking. The aim of this prospective observational study was to examine the relationship between maternal Hcy levels in early pregnancy and birth weight.

\section{Materials and methods}

The hospital is one of the largest maternity hospitals in Europe and cares for women from all socioeconomic groups across the urban-rural divide. Women were recruited at their convenience during their first prenatal visit between June 2014 and March 2016 after sonographic confirmation of an ongoing singleton pregnancy. Exclusion criteria were maternal age $<$ 18 years, multiple pregnancies, a history of a previous NTD, or an inability to understand English. Informed written consent was obtained. Women's clinical and sociodemographic details were computerized routinely and updated immediately after delivery. The Gestation Related Optimal Weight (GROW) bulk centile calculator v8.0.1 was used to convert birth weight (BW) to birth weight centiles [10]. The calculator adjusted birth weight for the following confounding variables: maternal ethnicity, maternal height and weight, parity, infant gender, gestation at birth, and birth weight. Small for gestational age (SGA) is defined as a birth weight centile $\leq 10$ th centile, large for gestational age (LGA) as a birth weight centile $\geq 90$ th centile, and appropriate for gestational age (AGA) if a BW centile is between the 10th and 90th centile.

At the time of taking the routine first visit blood tests, additional samples were taken for serum and RBC folate, serum vitamin B12, and plasma Hcy measurements. These samples were transported in a cool box within 4 hours of extraction for separation, storage at $-70^{\circ} \mathrm{C}$, and analysis. Plasma Hcy was measured using a Roche Cobas 8000 (c502) analyzer using AxisShield liquid stable 2-part homocysteine reagent. Serum and RBC folates were performed by a microbiological method, using a microtitre plate adaptation of the chloramphenicol-resistant Lactobacillus casei 
Table 1. Characteristics of the study population $(n=498)$.

\begin{tabular}{ll}
\hline Age $<30$ years $(\%, n)$ & $39.0(194)$ \\
Nulliparas $(\%, n)$ & $42.8(213)$ \\
Obese $(\%, n)$ & $19.4(97)$ \\
Planned Pregnancy $(\%, n)$ & $62.7(312)$ \\
Current Smoker $(\%, n)$ & $12.9(64)$ \\
Born in Ireland $(\%, n)$ & $74.7(371)$ \\
\hline
\end{tabular}

method [11]. Serum vitamin B12 was measured using a microtitre plate adaptation of the colistin-resistant microorganism Lactobacillus leichmannii after carrying out an initial extraction step [12]. A detailed questionnaire about all nutritional supplement intakes was completed under the supervision of a research dietitian (SC). To collect estimated habitual food intakes for the analysis of total dietary folate (natural folate and synthetic FA from fortified foods), women were asked to complete a retrospective 4-day Diet History (DH) under supervision. This was combined with a customized Food Frequency Questionnaire (FFQ) to capture the brand names of foods fortified with FA. This is because in Ireland FA is added to food on a voluntary basis and the amount added varies according to the brand. Information on socioeconomic status was assessed using questions from the European Union Survey on Income and Living Conditions [13].

Data from the participants' questionnaires were anonymized and coded on a Microsoft Excel ${ }^{\circledR}$ spreadsheet and statistical analysis was conducted using SPSS for Windows, version 20 (IBM Corporation, Armonk, NY, USA). The distribution of data for continuous variables was assessed for normality. Descriptive statistics were first used to characterize the study cohort. One-way ANOVA and independent-samples $t$-tests were used to compare mean Hcy levels with the time of initiation of FA supplementation in weeks. Pearson and Spearman's correlations were used to assess the correlation between Hcy and folate biomarkers, vitamin B12, and birth weight centile (depending on whether the variable was normally distributed or not). A one-way ANOVA with a Tukey post hoc test was used to investigate the association between maternal Hcy and birth weight centile groups (SGA, normal, or LGA). Multivariable regression analysis was used to assess the association between plasma Hcy and demographic factors. This study was approved by the Hospital's Research Ethics Committee in 2013 (Study number 27-2013).

\section{Results}

The characteristics of the study population are shown in Table 1 and they are similar to those reported in
Table 2. Mean (SD) total maternal homocysteine ( $\mu \mathrm{mols} / \mathrm{l}$ ) analyzed according to maternal characteristics.

\begin{tabular}{|c|c|c|}
\hline & Homocysteine $(\mu \mathrm{mols} / \mathrm{l})$ & $p$ \\
\hline \multicolumn{3}{|l|}{ Planned pregnancy } \\
\hline Yes $(n=312)$ & $6.9(1.9)$ & $<.001$ \\
\hline No $(n=186)$ & $7.5(2.5)$ & \\
\hline \multicolumn{3}{|l|}{ Parity } \\
\hline Nulliparous $(n=213)$ & $7.1(1.7)$ & .91 \\
\hline Multiparous $(n=285)$ & $7.1(2.4)$ & \\
\hline \multicolumn{3}{|l|}{ Married } \\
\hline Yes $(n=246)$ & $6.7(1.6)$ & $<.001$ \\
\hline No $(n=252)$ & $7.5(2.5)$ & \\
\hline \multicolumn{3}{|l|}{ Smoking } \\
\hline Current $(n=64)$ & $8.3(3.3)$ & $<.001$ \\
\hline Nonsmoker $(n=434)$ & $6.9(1.9)$ & \\
\hline \multicolumn{3}{|l|}{ Consistent Poverty } \\
\hline Yes $(n=13)$ & $8.7(4.0)$ & .16 \\
\hline No $(n=291)$ & $7.0(2.1)$ & \\
\hline \multicolumn{3}{|l|}{ Deprivation } \\
\hline Yes $(n=37)$ & $8.0(3.4)$ & .32 \\
\hline No $(n=412)$ & $6.8(1.6)$ & \\
\hline \multicolumn{3}{|l|}{ Relative income poverty } \\
\hline Yes $(n=74)$ & $8.0(3.4)$ & .007 \\
\hline No $(n=231)$ & $6.8(1.6)$ & \\
\hline \multicolumn{3}{|l|}{ Obesity } \\
\hline Obese $(n=97)$ & $7.2(2.4)$ & .67 \\
\hline Nonobese $(n=401)$ & $7.1(2.1)$ & \\
\hline \multicolumn{3}{|l|}{ Maternal Age (years) } \\
\hline$<30(n=194)$ & $7.6(2.7)$ & $<.001$ \\
\hline$\geq 30(n=304)$ & $6.8(1.6)$ & \\
\hline \multicolumn{3}{|l|}{ Preconceptional FA } \\
\hline Yes $(n=213)$ & $6.8(2.0)$ & $<.001$ \\
\hline No $(n=285)$ & $7.4(2.2)$ & \\
\hline \multicolumn{3}{|l|}{ County of residence } \\
\hline Dublin $(n=317)$ & $7.2(2.2)$ & .5 \\
\hline Outside Dublin $(n=181)$ & $7.0(2.1)$ & \\
\hline \multicolumn{3}{|l|}{ Third Level Education } \\
\hline Yes $(n=270)$ & $6.8(1.8)$ & .01 \\
\hline No $(n=178)$ & $7.4(2.4)$ & \\
\hline Country of birth & $7.4(2.3)$ & \\
\hline Ireland $(n=371)$ & $6.6(1.4)$ & Reference Category \\
\hline *EU $14(n=32)$ & $6.7(1.5)$ & .15 \\
\hline *EU $13(n=54)$ & $5.9(1.1)$ & .10 \\
\hline Other $(n=41)$ & & $<.001$ \\
\hline \multicolumn{3}{|l|}{ Folic Acid in pregnancy } \\
\hline Yes $(n=484)$ & $7.1(2.1)$ & $<.001$ \\
\hline No $(n=9)$ & $10.2(4.0)$ & \\
\hline
\end{tabular}

SD: standard deviation.

*EU 14 (Austria, Belgium, Finland, France, Germany, Greece, Italy, Luxembourg, Netherland, Portugal, Spain, Sweden, UK).

*EU13 (Cyprus, Czech Republic, Estonia, Hungary, Latvia, Lithuania, Malta, Poland, Slovenia, Slovakia, Romania, Bulgaria, Croatia).

the Annual Hospital Clinical Report [14]. The relationship between plasma mean (SD) Hcy and maternal variables is shown in Table 2.

On multiple regression analysis, after controlling for those factors which were significant predictors of Hcy levels on univariate analysis (pregnancy intention, marital status, smoking status, relative income poverty, age, preconceptional FA use, FA during pregnancy, country of birth and third level education), only smoking $(\beta=0.169, \quad p=.009)$, relative income poverty $(\beta=0.129, \quad p=.037)$, and Irish nativity $(\beta=0.144$, $p=.009)$, remained predictive of having a higher Hcy level. 
There was no difference between Hcy levels and BW centile grouping (comparing SGA and AGA $p=.092$, SGA and LGA $p=0.058$ and AGA and LGA $p=.498)$. This was true whether the woman reported smoking or not. There was no relationship between birth weight centile and Hcy for either smokers $(r=0.0001, p=.98)$ or nonsmokers $(r=-0.007$, $p=.097)$. There was also no association between RBC folate, plasma folate and plasma vitamin B12 and infant birth weight centile (RBC folate and BW centile $-r=-0.033, p=0.482$, plasma folate and BW centile $-\rho=0.051, p=.274$ and plasma vitamin B12 and BW centile $-\rho=0.078, p=.090$ ).

There was a negative association between maternal Hcy and serum folate $(r=-0.285, p<.001)$ and RBC folate $(r=-0.353, p<.001)$, and between maternal Hcy and vitamin B12 measurements $(r=-0.260$, $p<.001)$. There was no association between maternal Hcy and maternal total dietary folate $(r=-0.062$, $p=.32)$ or dietary vitamin B12 $(r=-0.084, p=.18)$ (See supplementary data). There was also no association between maternal Hcy and the duration of FA supplementation in weeks $(r=-0.08, p=.083$ ) (see Supplementary Table 1) or between maternal Hcy and gestational age at phlebotomy $(r=-0.54, p=.35)$.

Within the population studied, there was excellent compliance with folic acid supplementation at the time of the first prenatal visit (98.2\%) with just 3.6\% $(n=18)$ of women with a plasma folate level below that considered as deficient $(<10 \mathrm{nmol} / \mathrm{L})$ and $1.0 \%(n=5)$ deficient based on RBC folate $(<340 \mathrm{nmol} / \mathrm{l})$. There was a higher rate of vitamin B12 deficiency within the cohort with $19.5 \%(n=98)$ of women studied with a plasma vitamin B12 level below $150 \mathrm{pmol} / \mathrm{L}$.

\section{Discussion}

In this prospective observational study of women in early pregnancy, we found that maternal Hcy levels did not correlate negatively with birth weight centiles. On linear regression analysis, Hcy did correlate negatively with selfreported smoking, relative income poverty, and Irish nativity.

Our study has strengths. Detailed clinical, sociodemographic, dietary intakes, and vitamin supplementation details were collected under the supervision of a single researcher in the same cohort of participants in early pregnancy. Phlebotomy was performed at the same visit to measure Hcy and other associated nutritional biomarkers vitamin B12 and folate. A limitation is that information on maternal smoking was selfreported and not verified by biochemical testing. It is also notable that this study was undertaken in a country where folate food fortification is voluntary and not mandatory. Compliance with FA supplementation at the time of recruitment was high.

In a Spanish study of 93 pregnant women aged 18-35 years, the neonates of mothers in the highest tertile of plasma Hcy measured before pregnancy, at 8-week gestation, and again in labor, weighed less than neonates born to mothers in the low-medium tertiles [5]. All the pregnancies were planned, but the women did not take FA in the first trimester.

In an Australian study of 137 women at 18-20week gestation, women with intrauterine growth restriction (IUGR) had an increased plasma Hcy concentration compared with controls $(p<.001)$ [13]. Those who had a pregnancy complicated by IUGR were more likely to smoke than controls $(p<.004)$. Women who smoked during pregnancy, however, had an average plasma Hcy level that was $27 \%$ higher than nonsmokers.

In a systematic review and meta-analysis of maternal Hcy and SGA offspring, 19 studies were identified with 21,326 participants [15]. Higher maternal Hcy concentrations were associated with a small increased risk of SGA. The study estimated that birth weight decreased $31 \mathrm{~g}$ for every $1 \mathrm{SD}$ increase in maternal $\mathrm{Hcy}$. The clinical relevance of this decrease was uncertain. Of the eight studies that used regression analysis, only two adjusted for smoking and both of these studies measured maternal Hcy in the third trimester.

Previous reports have also associated an increased Hcy with different obstetric complications including abruptio placentae, preeclampsia, stillbirth, and recurrent miscarriage as well as NTDs $[6,16]$. This has led to the suggestion that FA supplementation could potentially reduce the risk of obstetric complications related to high levels of maternal Hcy [5]. Due to the inverse relationship between folate and vitamin B12 levels and $\mathrm{Hcy}$, it is important that the status of these biomarkers is investigated in parallel with Hcy. We have previously demonstrated that obese women in this cohort were found to have lower levels of plasma folate and plasma vitamin B12 compared to women with a normal BMI $(\rho=-0.100, p=.300$ and $\rho=-0.100, p=.026)$ [17]. Other studies have also shown that a higher folate level can be protective against the effect of genetic variation in the MTHFR enzyme that results in reduced efficiency in the breakdown of Hcy to methionine [18]. Our findings suggest that any epidemiological associations between increased maternal Hcy and adverse pregnancy outcomes may be influenced by other factors such as smoking or social disadvantage. 
In conclusion, the absence of an association between maternal plasma Hcy and birth weight in this well-characterized population following multiple linear regression analysis means that future studies that examine the relationship between intrauterine fetal growth and maternal nutrient measurements in pregnancy need to correct for confounding variables which influence fetal growth, particularly maternal smoking.

\section{Acknowledgements}

We thank the women who participated and our laboratory and midwifery colleagues, particularly Ruth Harley and Muireann Ní Mhurchu from the Hospital's Biobank, for their assistance. We thank the all-island body Safefood for funding this research.

\section{Disclosure statement}

No potential conflict of interest was reported by the authors.

\section{Funding}

This work was supported by Safefood, an all-island body funded under the Good Friday Agreement, grant number [02-2015]. The researchers are independent from funders.

\section{ORCID}

Eimer G. O'Malley (D) http://orcid.org/0000-0002-8100-4761

\section{References}

[1] Ubeda N, Reyes L, González-Medina A. Physiologic changes in homocysteine metabolism in pregnancy: a longitudinal study in Spain. Nutrition. 2011;27: 925-930.

[2] Megahed MA, Taher IM. Folate and homocysteine levels in pregnancy. Br J Biomed Sci. 2004;61:84-87.

[3] Bjørke Monsen ALB, Ueland PM. Homocysteine and methylmalonic acid in diagnosis and risk assessment from infancy to adolescence. Am J Clin Nutr. 2003;78: 7-21.

[4] Walker MC, Smith GN, Perkins SL, et al. Changes in homocysteine levels during normal pregnancy. Am J Obstet Gynecol. 1999;180:660-664.
[5] Murphy MM, Scott JM, Arija V, et al. Maternal homocysteine before conception and throughout pregnancy predicts fetal homocysteine and birth weight. Clin Chem. 2004;50:1406-1412.

[6] Mills JL, McPartlin JM, Kirke PN, et al. Homocysteine metabolism in pregnancies complicated by neuraltube defects. Lancet. 1995;345:149-151.

[7] Yang M, Li W, Wan Z, et al. Elevated homocysteine levels in mothers with neural tube defects: a systematic review and meta-analysis. J Matern Fetal Neonatal Med. 2016;3:1-7.

[8] Mascarenhas M, Habeebullah S, Sridhar MG. Revisiting the role of first trimester homocysteine as an index of maternal and fetal outcome. J Pregnancy. 2014;2014:1.

[9] Yajnik CS, Deshpande SS, Jackson AA, et al. Vitamin B12 and folate concentrations during pregnancy and insulin resistance in the offspring: the Pune Maternal Nutrition Study. Diabetologia. 2007;51:29-38.

[10] Gardosi J, Francis A, Turner S, et al. Customized growth charts: rationale, validation and clinical benefits. Am J Obstet Gynecol. 2018;218:S609-S618.

[11] Molloy AM, Scott JM. Microbiological assay for serum, plasma, and red cell folate using cryopreserved, microtiter plate method. Methods Enzymol. 1997;281: 43-53.

[12] Kelleher BP, Broin SD. Microbiological assay for vitamin B12 performed in 96-well microtitre plates. J Clin Pathol. 1991;44:592-595.

[13] Central Statistics Office. European Union (EU) survey on Income and Living Conditions (EU-SILC) 2011 and Revised 2010 Results. Dublin (Ireland): Central Statistics Office; 2013.

[14] Coombe Women and Infants University Hospital annual clinical Report 2014; [cited 2018 Jan 14]. Available from: http://www.coombe.ie/index. php? nodeld $=110$

[15] Furness D, Fenech $M$, Dekker $G$, et al. Folate, vitamin B12, vitamin B6 and homocysteine: impact on pregnancy outcome. Matern Child Nutr. 2013;9: 155-166.

[16] Hogeveen M, Blom HJ, den Heijer M. Maternal homocysteine and small-for-gestational-age offspring: systematic review and meta-analysis. Am J Clin Nutr. 2012;95:130-136.

[17] O'Malley EG, Reynolds CME, Cawley S, et al. Folate and vitamin B12 levels in early pregnancy and maternal obesity. Eur J Obstet Gynecol Reprod Biol. 2018; 231:80-84.

[18] Relton CL, Pearce MS, Burn J, et al. An investigation of folate-related genetic factors in the determination of birthweight. Paediatr Perinat Epidemiol. 2005;19: 360-367. 